\title{
THE RESTORATION OF THE MEDIEVAL WALLS OF SAN GINESIO: A DEDICATED STUDY FOR THE CONSERVATION, REPAIR AND ENHANCEMENT OF AN IMPORTANT MILITARY FORTIFICATION
}

\author{
M. SARACCO ${ }^{1 *}$, F. MARIANO ${ }^{2}$, A. A. GIULIANO ${ }^{2}$, \\ L. PETETTA ${ }^{2}$ AND F. PICCININI ${ }^{2}$ \\ ${ }^{1}$ Dipartimento di Scienze della Formazione, dei beni culturali e del turismo (Sfbct) \\ Università di Macerata (UniMC) \\ P.le Luigi Bertelli, 1 - C.da Vallebona 62100 Macerata \\ e-mail: mauro.saracco@unimc.it (*corresponding author) \\ ${ }^{2}$ Dipartimento di Ingegneria Civile, Edile e Architettura (DICEA) \\ Università Politecnica delle Marche (Univpm) \\ Via Brecce Bianche, 60131 Ancona, Italy \\ email: \{f.mariano, f.piccinini\}@univpm.it, \{giuliano.andrea, leonardo.petetta\}@gmail.com
}

Keywords: military fortification, analysis, knowledge, conservation

\begin{abstract}
The seismic events that occurred in central Italy in 2016 severely damaged the rich cultural heritage system present in the area hit by the earthquake. Particularly significant is the situation of the Marche Region, here it is necessary to intervene quickly and effectively in order to preserve and secure the damaged historical architectural heritage. Following the agreement signed in 2019 between the administration of the Municipality of San Ginesio and the Marche Polytechnic University, a collaboration has been established, which is the basis of the present research work, aimed at studying and deepening the possible actions to be undertaken to be able to repair, preserve and enhance the medieval walls of the city. The city walls, dating from the fourteenth century A.D., almost completely surround the historic center of the city and are characterized by the presence of a large part of the ancient fortifications such as towers, access doors, defensive walkways, loopholes, etc. Since there is no complete survey of the planimetric configuration and of the elevations of the medieval walls, updated to the situation created after the earthquake, the first phase of the research focused on data acquisition. Combining DJI Spark MMA1 photogrammetric UAV images with cloud point by Mobile laser SLAM Kaarta Stencil, the 3D-dimensional modelling of the walls was obtained with the accuracy related to the output scale of 1:200 and with a detail and complexity useful for the following conservative analysis. Once the data was acquired and processed, it was possible to carry out a complete analysis of the walls structure, identifying the materials and construction techniques, the state of preservation of the materials, the damage situation to the structures, the various construction phases with the consequent relative dating. The analytical phase was concluded, therefore, with the identification and cataloging of the types of walls present. Each of these has been characterized both from a typological and a technicalconstruction point of view, defining the wall quality (IQM) and the consequent mechanical parameters through the calculation process of the Wall Quality Index.
\end{abstract}




\section{INTRODUCTION}

The seismic events that occurred in central Italy in 2016 severely damaged the rich cultural heritage system present in the area hit by the earthquake. Particularly significant is the situation of the Marche Region, here it is necessary to intervene quickly and effectively in order to preserve and secure the damaged historical architectural heritage.

Following the agreement signed in 2019 between the administration of the Municipality of San Ginesio and the Marche Polytechnic University, a collaboration has been established, which is the basis of the present research work, aimed at studying and deepening the possible actions to be undertaken to be able to repair, preserve and enhance the medieval walls of the city. Specifically, the research program was divided into:

- first phase: acquisition through appropriate geomatical instrumentation of the data necessary for geolocation and three-dimensional reconstruction of the objects under investigation;

- second phase: documentary research for the reconstruction of the historical / construction evolution of the objects being studied and for the identification of the restoration interventions carried out over time;

third phase: analysis and architectural graphing of the city walls and fortifications being studied by the creation of appropriate technical drawings; study and representation of the state of the materials degradation of surfaces and crack patterns by drafting dedicated thematic maps; definition of the wall quality and the related mechanical parameters of the historical walls through the process of calculating the Wall Quality Index (IQM).
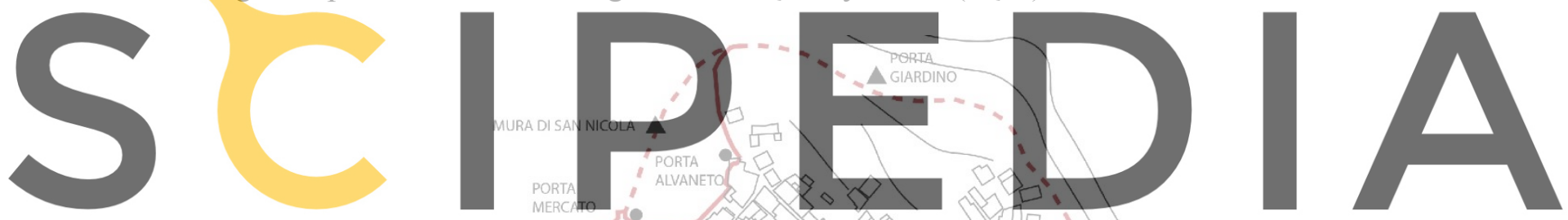

Register for free at https//www.Scipedia, com to downtoad the version without the watermark

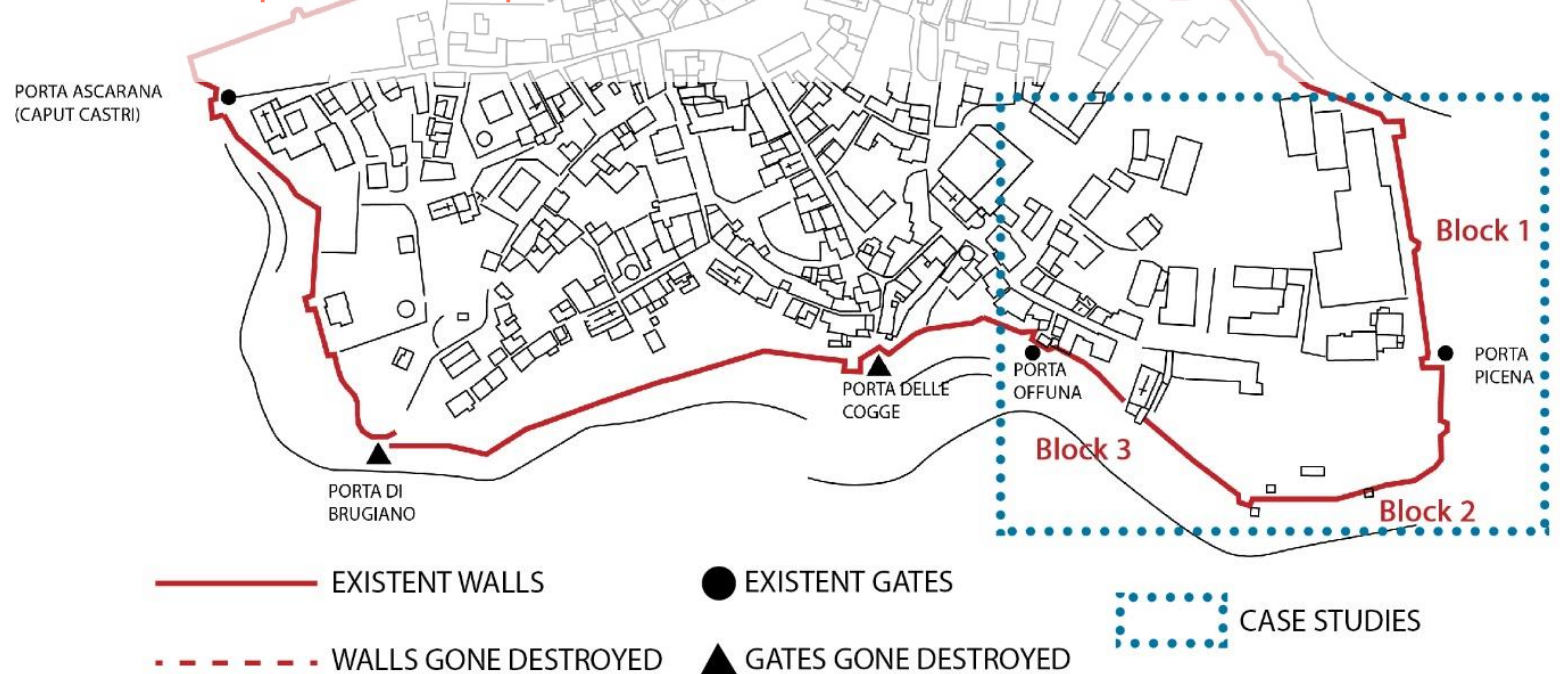

Figure 1: Planimetric diagram of the city walls with identification of case studies 
Given the significant planimetric development of the city walls (about $4.5 \mathrm{~km}$ in length) and given the presence of vegetation that completely obliterates some portions of the walls, it was decided to operate at first, also in order to validate the methodology described above, on three case studies portions, significant in size and type of the walls themselves. The three case studies, contiguous with each other, are constituted by: "Block 1" that extends from the first tower of the portion of walls placed at the east of the town up to Porta Picena; "Block 2" which continues from Porta Picena to the corner tower of the walls placed in the South; "Block 3" which extends from the latter tower to the Porta Offuna (Fig. 1).

The working group, led by the scientific managers of the research who are Prof. Fabio Mariano and Prof. Eva Savina Malinverni (Univpm), is composed of: Prof. Mauro Saracco (UniMC), Leonardo Petetta and Andrea A. Giuliano (PhD, Univpm), Chiara Mariotti (researcher, Univpm), Stefano Chiappini, Fabio Piccinini, Francesco Di Stefano (PhD Students, Univpm) and by students of the "Architectural Restoration" course (Degree course "Ingegneria Edile-Architettura", Univpm)

\section{THE MEDIEVAL WALLS OF SAN GINESIO}

\subsection{Historical background}

The urban layout of San Ginesio is typical of a fortified medieval town whose economy has always been based mainly on trade. The residential buildings, in fact, mainly consist of terraced houses, often with shops in ground floor, that overiooking on the main streets that connect the square to the various city gates. Added to this is the location and important religious construction of numer hospitals in the town. completely surround the that are the adaptation to the rough orography of the land. Still today, along the route of the

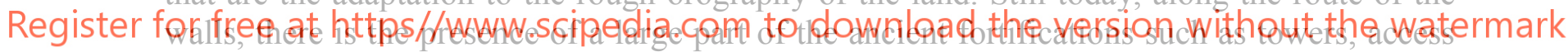

gates, walkways, loopholes, etc. Of particular interest are the shapes and volumes of all surviving access gates (both the original ones and those destroyed and rebuitt in the nineteenth century) that date back to the interventions of the second half of the fourteenth century. The walls, whose official construction date dates back to 1308 as reported by the documents of the Public Council, seem to exist in reality from much earlier, as it emerges from numerous deeds of sale and parchments found that the city was already largely fortified at early 1300. It is supposed, in fact, that the interventions of 1308 did not concern the construction from scratch of the city walls but rather the completion of the missing parts and the restoration of the degraded and / or collapsed portions of the same. Always in the 14th century, a large urban expansion project was also drawn up for the city of San Ginesio, which was to consider the walls too, but due to the wars with the municipality of Fermo and the plague epidemic that hit the city, it was never realized. Throughout the fifteenth century, however, attempts were made to continue at least the project of the walls, so much so that in 1414 the Public Council of the city decided that each new Podestà would have to donate part of his salary proper for the construction of the city walls and even the Papal State, although showing the intention not to invest funds in this part of its territory, authorized the works for the walls and granted tax reliefs 
for this purpose. From the eighteenth century there is no more evidence of restoration or maintenance work carried out on the city walls. Over time these deteriorated so much that at the end of the 19th century there was no longer trace of the Porta di Brugiano [2]. We will have to wait until the unification of Italy to see again interest in bringing to light the majesty of this important fortified work. In fact, in the 19th century, operations of complete reconstruction were carried out on entire portions of the walls, such as, for example, for the stretch that goes from Porta Ascarana to Porta Alvaneto [3].

\subsection{The restoration work carried out}

A documentary research was carried out aimed at the classification and knowledge of the restoration interventions that have occurred over time on the city walls. This operation allowed a correct reading of the state of affairs of the city walls and its fortifications and was indispensable for identifying correctly and effectively the new conservation and restoration interventions to be put in place. Documents regarding the proposals for intervention, the metric calculations and the technical drawings found in the archives of the Soprintendenza Archivistica e Bibliografica dell'Umbria e delle Marche were analyzed. Below The main interventions carried out over time are listed briefly and in chronological order.

1887 - Restoration of Porta Picena and Porta Offuna. The ruins of the Porta Picena's pre-gate were razed to the ground and the crenellated (in Guelph style) crown of Porta Offuna was rebuilt;

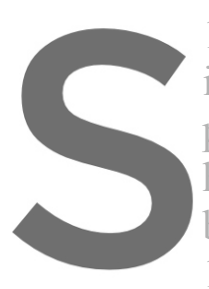
1977/1979 - Repair interventions of: exca points of collapse or hydraulic lime morta balustrade; demolition of especially in the top and roof parts, had lesions in the walls above the openings, in the corner

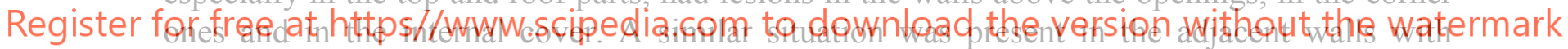

detachments in the top part. The repairs works involved: execution of perforations carried out on all walls and positioning of special steel bars blocked with fluid grouts; execution of niches for housing anchoring steel plates inserted inside the masonry such as not to be visible from the outside; repair of all lesions by recessed grouting performed with mortars similar to the existing ones.

1983 - In addition to the interventions of 1981, a technical report was drawn up with which requests were made to increase the resistance of the walls to both vertical and horizontal forces (with the execution of injections of cement-based binders and sewing irons placed every $3 \mathrm{~m}^{2}$ of wall) and to anchor the corners of the tower in order to reach the necessary resistance to the moments created by the horizontal forces. All this because the masonry was generally in a poor state of conservation with mortars degraded to $80 \%$ (if not absent in some sections) and with ramified cracks over the entire surface.

1984 - Reinforcement operations were carried out in the polygonal tower and in the surrounding wall sections by means of perforations of fluid grout reinforced with ribbed steel bars.

1988 - In the portion of the wall that goes from the polygonal tower until it almost reaches Porta Brugiano, restoration and consolidation works were carried out on the structures in relation to 
the severe deterioration they were experiencing due to the 1979 earthquake. In particular, the Porta Offuna and the church tower were treated specifically through: removal of the internal covering of Porta Offuna; removal of detrital material on the hospital tower; application of a tarred reinforced sheath; formation of an internal roof covering in Porta Offuna with ancient tiles of which $50 \%$ are recovered; formation of waterproof surface grouting with specific mortars; new floorings made by with ancient terracotta tiles in the towers; restoration of water collection and drainage terminals with terracotta pipes; grouting the joints of the existing masonry with hydraulic mortar.

1997 - General consolidation works were carried out following the earthquake of the same year. 2003 - Cleaning and consolidation works were carried out on Porta Offuna, Porta Alvaneto and on some sections of the walls. These works consisted in: hydro-washing of the entire exposed internal and external walls; plastering of the exposed internal and external masonry walls; recovery of the damaged masonry.

2005 - Consolidation works were carried out following the collapse of an entire portion of the walls between Porta Picena and Porta Offuna.

2018 - Following the 2016 seismic events, on Porta Picena and on the portions of neighboring walls, pending the implementation of the definitive repairs, temporary safety measures were carried out. On the top of the walls, the stones not tied to the masonry at risk of collapse were dismantled, with the aim of guarding them and repositioning them with the restoration works. In addition, a containment net fixed to the masonry with mechanical anchors was placed on these points to reduce the risk of falling of the unremoved stone segments. Two towers were, however, surrounded on four sides with harmonie steel strands housed on a frame of vertical
the most critical points.

Since there is no complete survey of the planimetric configuration and of the elevations of

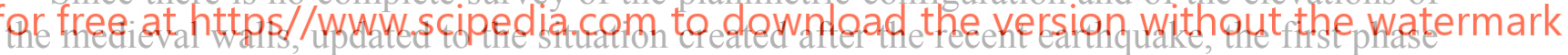

of the research focused on data acquisition aimed at obtaining a three-dimensional modelling of the wails. in order to create a compiete texturized 3D model of the walis, we decided to combine different techniques of acquisition. They include the aerial photogrammetry with UAV (Unmanned Aerial Vehicle) and the mobile laser scanner with a SLAM (Simultaneous Localization and Mapping) technology. This phase began with the definition of a reference system through a topographic survey, useful for the combination of the acquired images and the point clouds in the next data processing step. The photogrammetric survey of the walls was performed using a DJI Spark MMA1 drone and its integrated camera (Fig. 2a) [4]. For each section of the walls different flights were planned. Photos has been shot with the camera at different grades: nadir direction, $30^{\circ}$ and $45^{\circ}$ from the horizon, and frontal, covering a global field of view of approximatively $180^{\circ}$ and guaranteeing a high number of tie points (Fig. 2b). The survey was carried out maintaining the UAV camera at a constant distance of about $30 \mathrm{~m}$ from the wall, evaluating carefully both the flight time and the overlapping of the shots (Fig. $2 \mathrm{c})$ required to cover all the wall surface, obtaining an average Ground Sample Distance (GSD) of $4 \mathrm{~cm}$. 


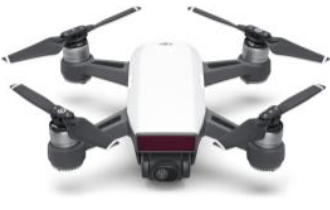

a)

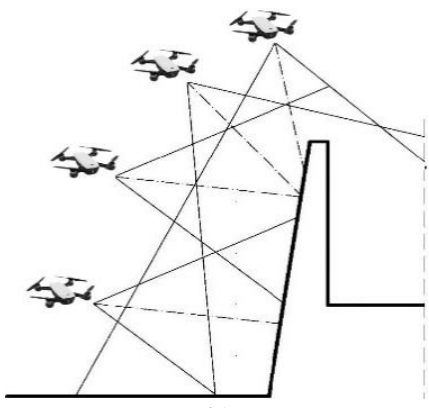

b)

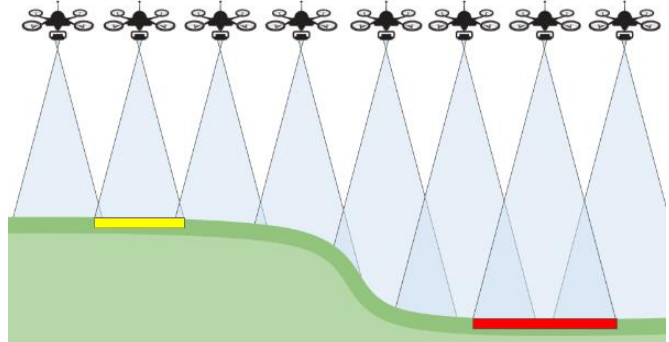

c)

Figure 2: a) DJI Spark MMA1 drone; b) UAV survey positions related to the vertical section of the walls; c) the method of photo overlapping

A survey campaign with the mobile laser scanner KAARTA Stencil 2 [5] was also planned to obtain 3D point clouds of the walls [6]. KAARTA Stencil 2 (Fig. 3a) is a light weight SLAM instrument, with an integrated system of mapping and real-time position estimation: it depends on LiDAR (Light Detection and Ranging) and IMU (Inertial Measurement Unit). The system uses Velodyne VLP-16 that consists on a band of 16 scan lines, with a $360^{\circ}$ field of view and a $30^{\circ}$ azimuthal opening. A tracker camera is integrated into the device to estimate the trajectory carried out during the acquisition operations. To realize this type of survey characterized by long close-loop paths, the laser scanner was mounted on a small pole held by hand. The progress of the scanning can be monitored in real time via an external monitor attached with a HDMI

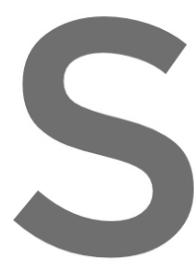
cable.

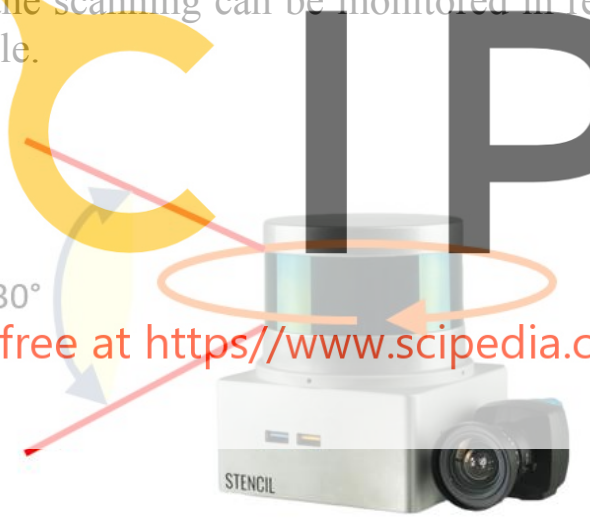

a)
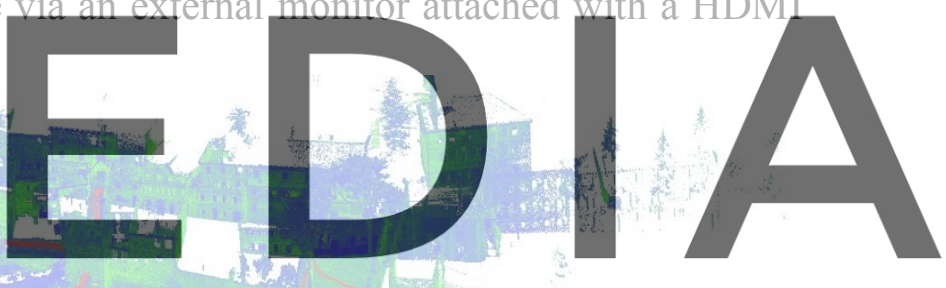

Register for free at https//www.scipedia.com to download the version without the watermark

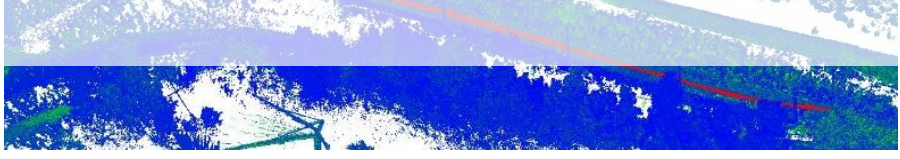

b)

Figure 3: a) KAARTA Stencil 2; b) the 3D point cloud and the estimated trajectory (red line) made by the mobile laser scanner (right)

The processing phase of the acquired data was conducted in laboratory using specific software. For the image processing, an Agisoft product [7] was used, justified by its good performance on image alignment from different points of view. During the image orientation step, the photos were set in the topographic network using control points for the bundle adjustment and so minimizing the orientation errors. After the images alignment, the resulting dense cloud was obtained through Structure from Motion (SfM) workflow, which allowed the creation of mesh surfaces and textured model. In case of 3D point cloud acquired by mobile laser scanner, the device have automatically processed data during the acquisition phase. Following, CloudCompare [8] is the software for the point cloud analysis that allows the post processing 
of the 3D data: registration and alignment of point cloud, manual or automatic cleaning, adoption of some filters to resample the point cloud that becomes lighter and clearly visible. KAARTA Stencil 2 has a strong potentiality to generate a higher number of points composing the $3 \mathrm{D}$ point clouds, but does not produce any visible colour information of the 3D points and so the UAV survey is able to compensate for this lack. It is clear that these technologies may be complementary to each other in creating complete high-quality 3D representations (Fig. 4). It is finally important to remark that the $3 \mathrm{D}$ model of the walls was realized with the accuracy related to the output scale of 1:200 and with a detail and complexity useful for the analysis and restoration activities.
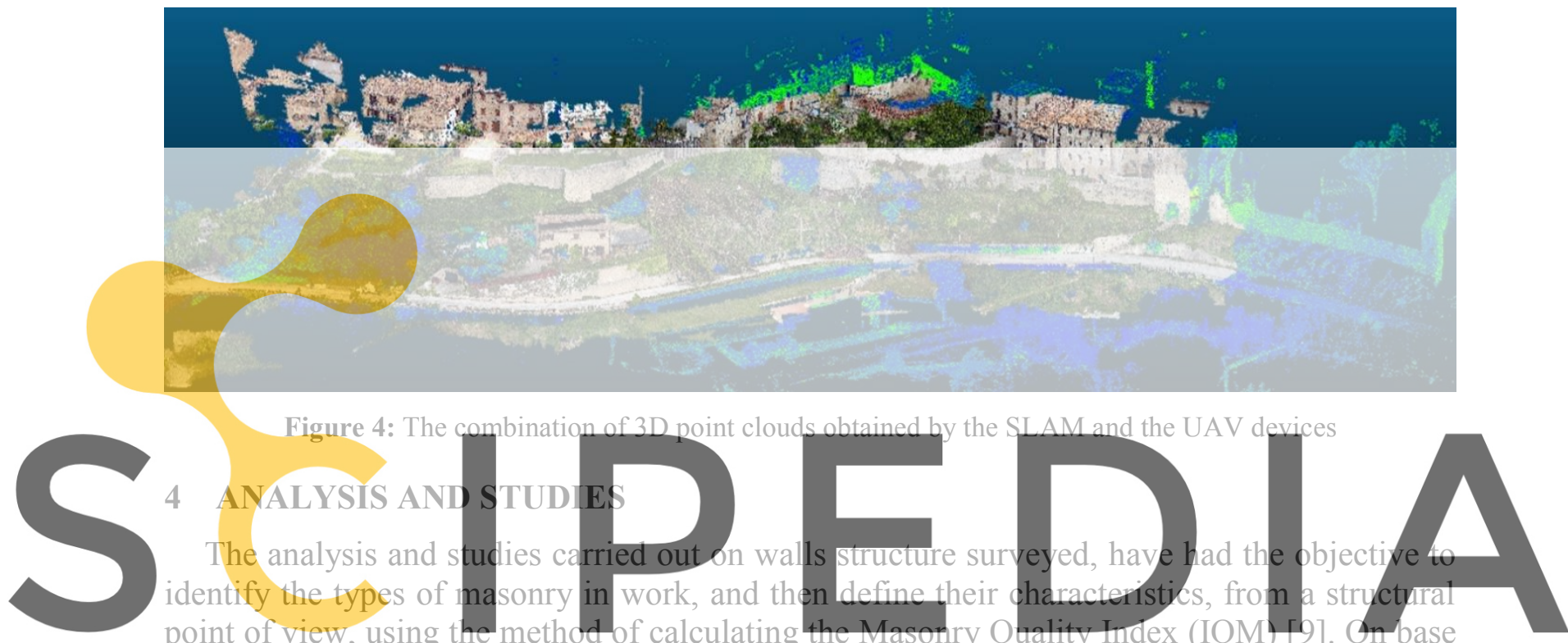

point of view, using the method of calculating th

of this calculation, it was possible to identify and delimit homogeneous portions of walls, which

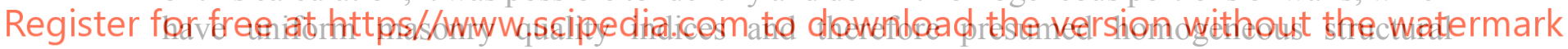

behaviors. These delimitations allowed to attribute, to the different types of masonry identified,

the main mechanical parameters, through the correlations identified by Borri and De Maria [11] between IQM and the classification of the masonry types, defined by the Instructions to the Italian Technical Code (Reference values of the mechanical parameters of the masonry: NTC 2008, tab. C8A.2 - NTC 2018, tab. C8.5.I). The results obtained, will allow to limit the number of invasive tests (double flat jacks) for the instrumental determination of the mechanical parameters, being able to relate the values thus recorded, with those derived from the analysis of the IQM.

\subsection{Identification and classification of materials and construction techniques}

Once the geometrical survey data was acquired and processed, it was possible to carry out a complete analysis of the walls structure. The first phase of analysis has been focused on the recognition and classification of the types of masonry present; this identification began with a visual survey of a series of parameters, aimed to describe the surface of the masonry, identifying the materials used, the processing of the surface of the blocks, the construction technique and the wall texture. This reconnaissance allowed a first generic subdivision of the walls present, 
(macro-type) followed by an in-depth analysis of the parameters deemed useful for their classification; in each macro-type, therefore, were chosen three significant samples, of one square meter, (for a total of 86 samples) and in each, were analyzed the size of the blocks and mortar joints, the presence and quality of the mortar, the methods of laying in works and wall texture (texture in façade and in cross section, existence of transversal connections). As a result, it was possible to classify 35 different types of masonry, in the three sections of walls analyzed. The presence of these numerous types of masonry, is due to different factors often integrated: different construction periods of the parts of the walls, repair works and/or reconstruction of some portions of these as a result of seismic events, overlapping walls of civil buildings or other structures.

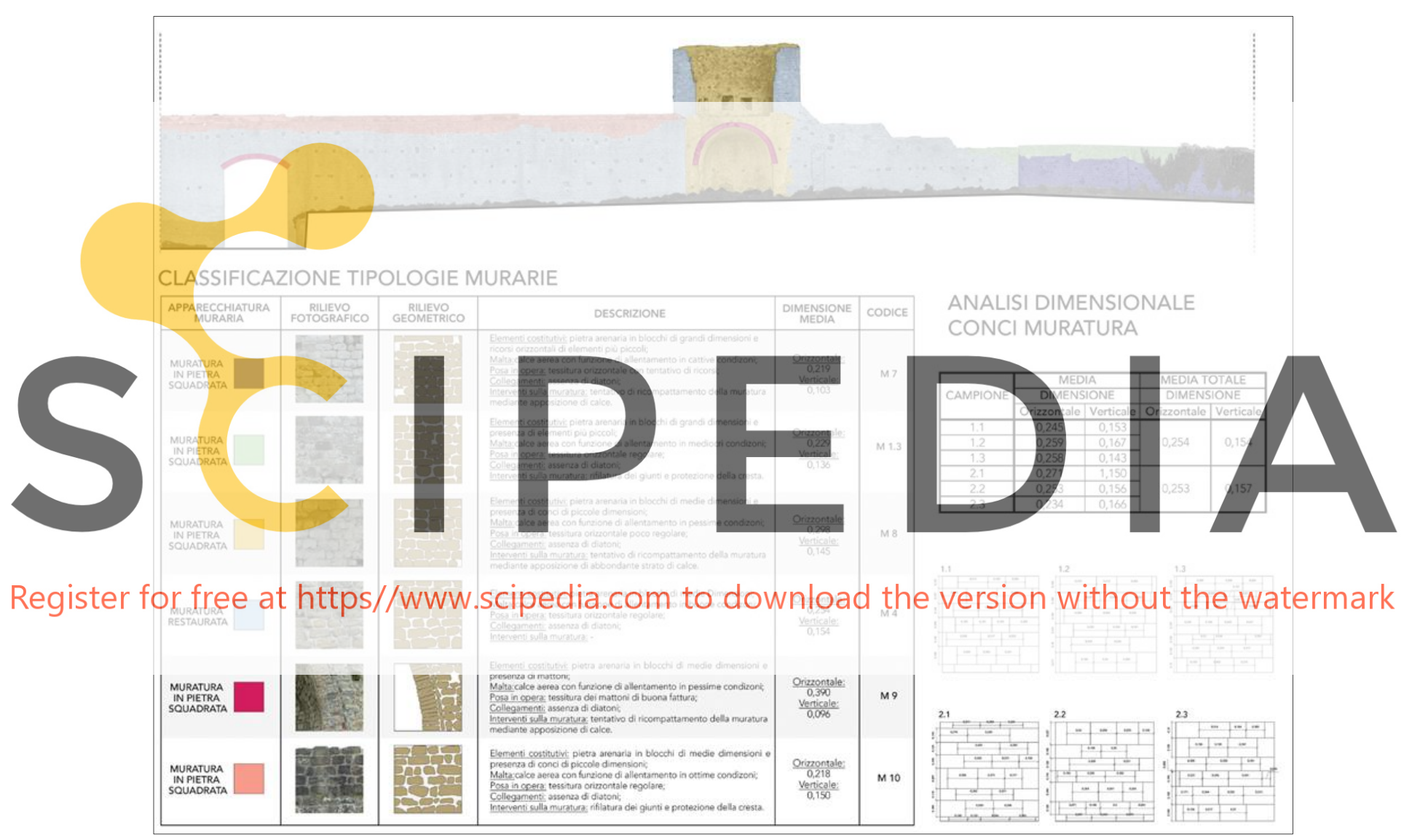

Figure 5: Datasheet for the classification of masonry types. In columns from left to right: type of wall texture, photographic survey of the sample, geometric survey of the sample, description of significant parameters, (constitutive elements, type of mortar, type of laying in work, cross connections) average block size, identification code. On the right, the block size survey and the average size estimate.

The types of masonry identified have been filed in summary tables, assigning each of them an identification code and a color so that they can be easily identified in the survey maps (Fig. 5). The datasheets contain images and the geometric survey of the samples used for classification, annotations relating to the constituent elements, mortars used, laying in the works and the texture of the wall, the possible presence of recent repair and/or restoration work; for this last 
aspect, the historical data collected with observations and the relevant data were compared.

\subsection{Materials decay and damage situation to the structures}

Since the degradation of the materials present in a structure, represents a process of pathological alteration, capable of compromising the chemical and physical-mechanical characteristics of the same, determining the state of preservation of the elements in work, it was essential to assess the strength characteristics of the masonry. It is also important to remember that the IQM calculation method uses qualitative assessment parameters of the conservation status of the mortar and building blocks of the masonry, therefore related to the possible presence of pathological alterations. The analysis of the degradation was carried out, at this stage, through a logical deductive path that, starting from the macroscopic alteration phenomena of the analyzed elements, derived the causes and mechanisms of degradation. The observations made, as indicated, were of a macroscopic type and therefore aimed at identifying forms of pathological alteration that obviously compromise the physical and mechanical characteristics of stone elements and mortar. In this analysis process, the Lexicon of macroscopic alterations of natural and artificial stone materials was used, collected in the UNI standard 11182:2006. The classification of the identified degrades, was transferred to the survey papers through a symbolism consisting of alphanumeric codes and colors. The recording of the forms of degradation was completed with the survey of the cracking framework and its interpretation, indicating static failures and the main mechanisms of damage related to dynamic stresses. The main forms of degrada

constitutes the blocks o been detected in numer areas and ridges of the masonry affected by rotations plan, derived from the seismic stresses of 2016
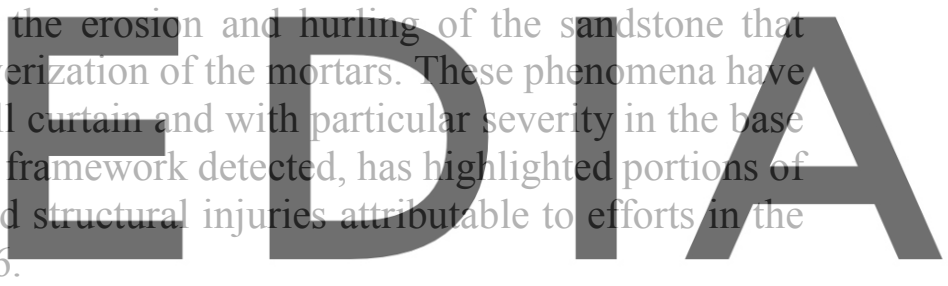

Register for free at https//www.scipedia.com to download the version without the watermark

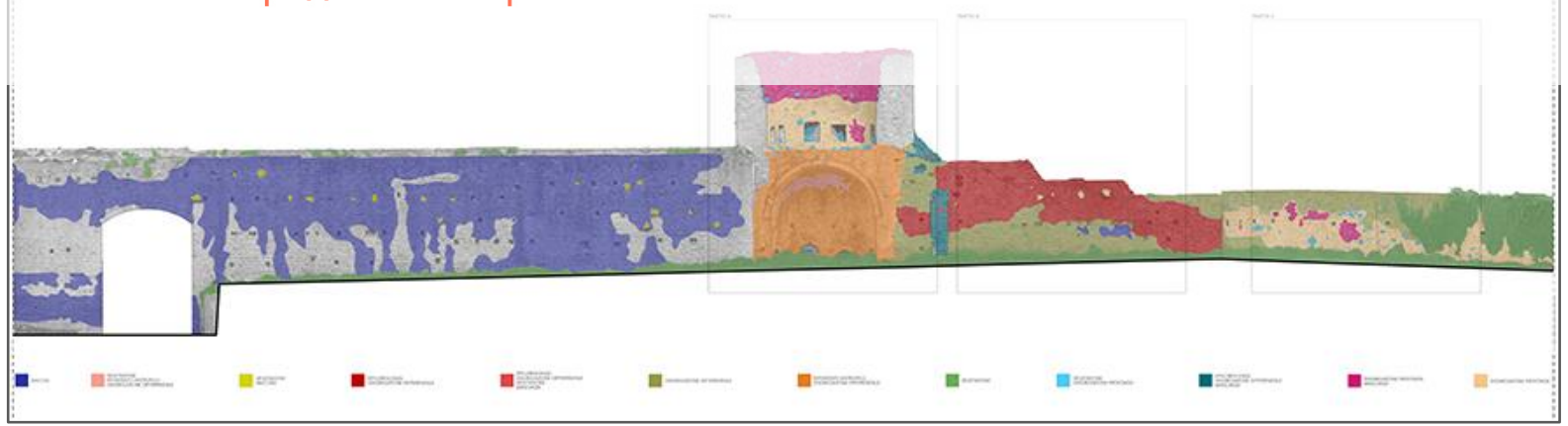

Figure 6: inside front, Block 2. A false-color representation of the main forms of degradation and their extent

\subsection{Wall Quality Index (IQM)}

The analytical phase was concluded, therefore, with the identification and cataloging of the types of walls present. Each of these has been characterized both from a typological and a technical-construction point of view, defining the wall quality (IQM) and the consequent mechanical parameters through the calculation process of the Wall Quality Index [9]. The 
procedure for the assessment of a Masonry Quality Index (IQM) is based on the identification of the masonry buildings typical features, evaluated with respect to the "rules of art" as reported in ancient and modern handbooks; from the visual inspection of masonry texture in façade and in cross section, a numerical evaluation is given to different parameters and a quality index can be obtained [10]. Among the innovations introduced, it is worth highlighting that the evaluation of the IQM is performed by defining the masonry quality as a function of the load type examined: 1) vertical loads; 2) horizontal in-plane loads; 3) horizontal out-of-plane loads [9]. Moreover, a correlation between the masonry quality index and the values of the mechanical parameters proposed in the tab. C8A.2 of the Instructions to the Italian Technical Code 2008 (updated in the tab. C8.5.I, of the Italian Technical Code 2018) has been proposed [11-12]; in particular a relationship aimed to provide values of mechanical parameters "coherent" to those proposed in the two tables mentioned, a function of the IQM has been obtained.

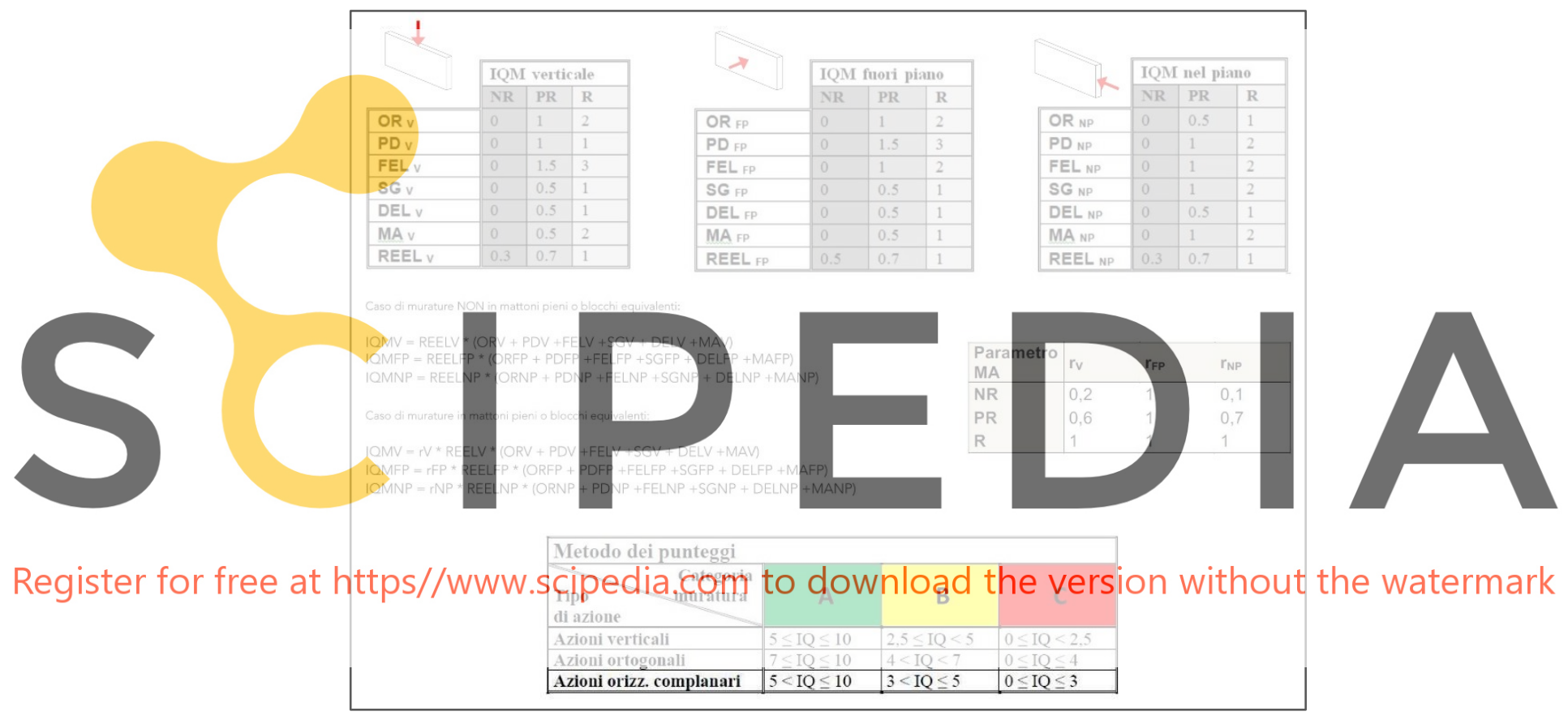

Figure 7: The IQM is divided according to the direction of the soliciting action into 3 indices: IQM for vertical actions, for horizontal actions out of plane and for horizontal actions in the plane. Based on compliance with the parameters of the "rule of the art", are assigned judgments of partial respect, respect and disrespect, to which some scores are connected. These scores are inserted in formulas that allow to obtain a global value for the three IQM, taking account the corrective parameters linked to the quality of mortar. The last table shows, on the basis of the obtained values, the masonry categories: $\mathrm{A}, \mathrm{B}$ and $\mathrm{C}$, of which $\mathrm{A}$ is the best and $\mathrm{C}$ the worst.

The calculation of IQM was carried out on all masonry samples surveyed, (so in three samples for each type of masonry) to obtain representative average values. The results showed low and medium, masonry quality indices in block 1, both for vertical loads, both for those horizontal in-plane and out of plane, while the situation in blocks 2 and 3 was appeared better, since only a single section has obtained a low masonry quality index for all expected loads (vertical, horizontal out of the plane, horizontal in the plane). 


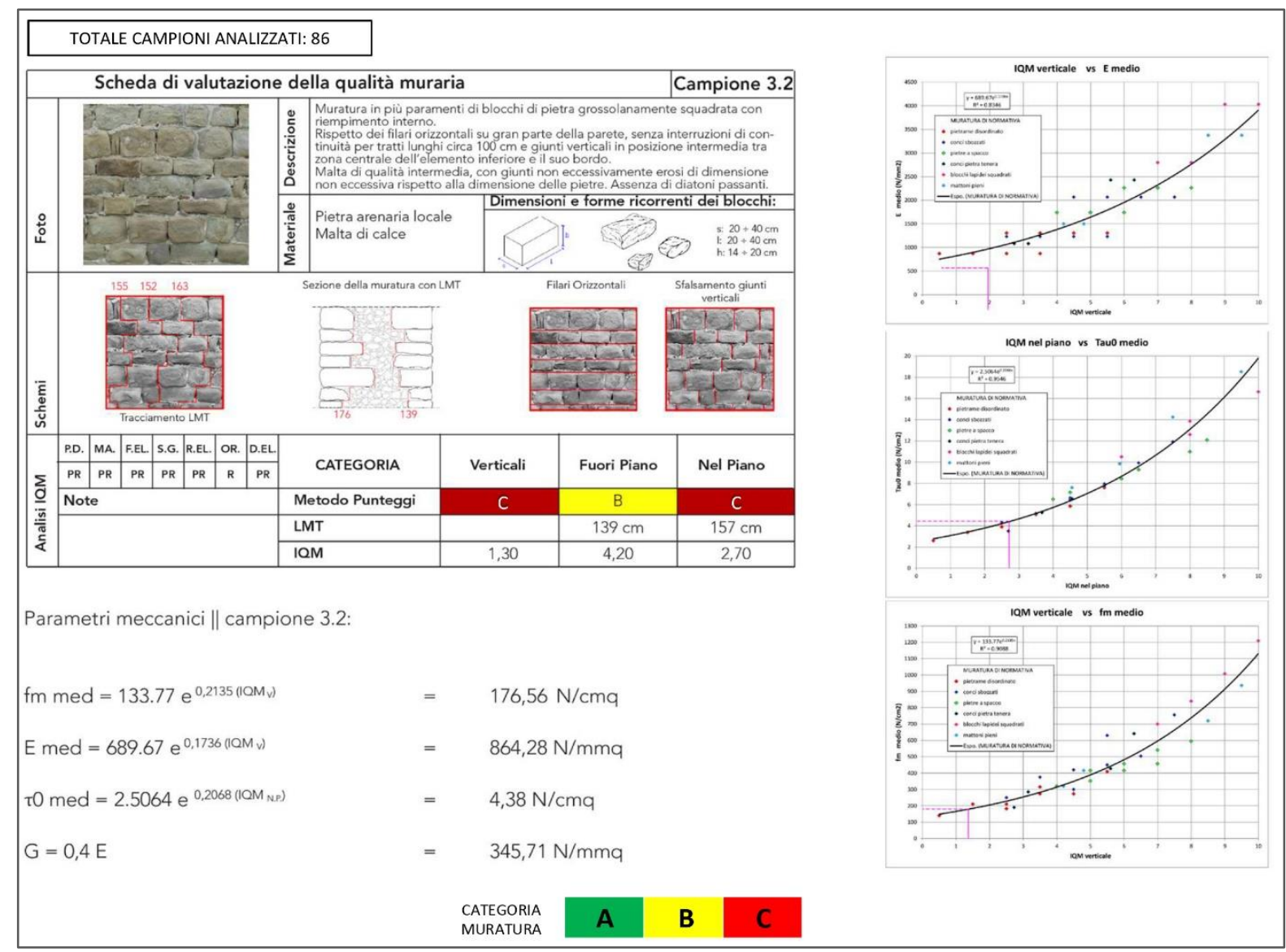

Figure 8: IQM analysis sheet, made for each sample of masonry detected. On the right, the correlation curves with the mechanical values, taken from Italian Technical Code 2008, tab. C8.A.2.

\section{ACTION IN-PLANE}

CATEGORIA MURATURA

A B

B $\quad$ C

BLOCK 1
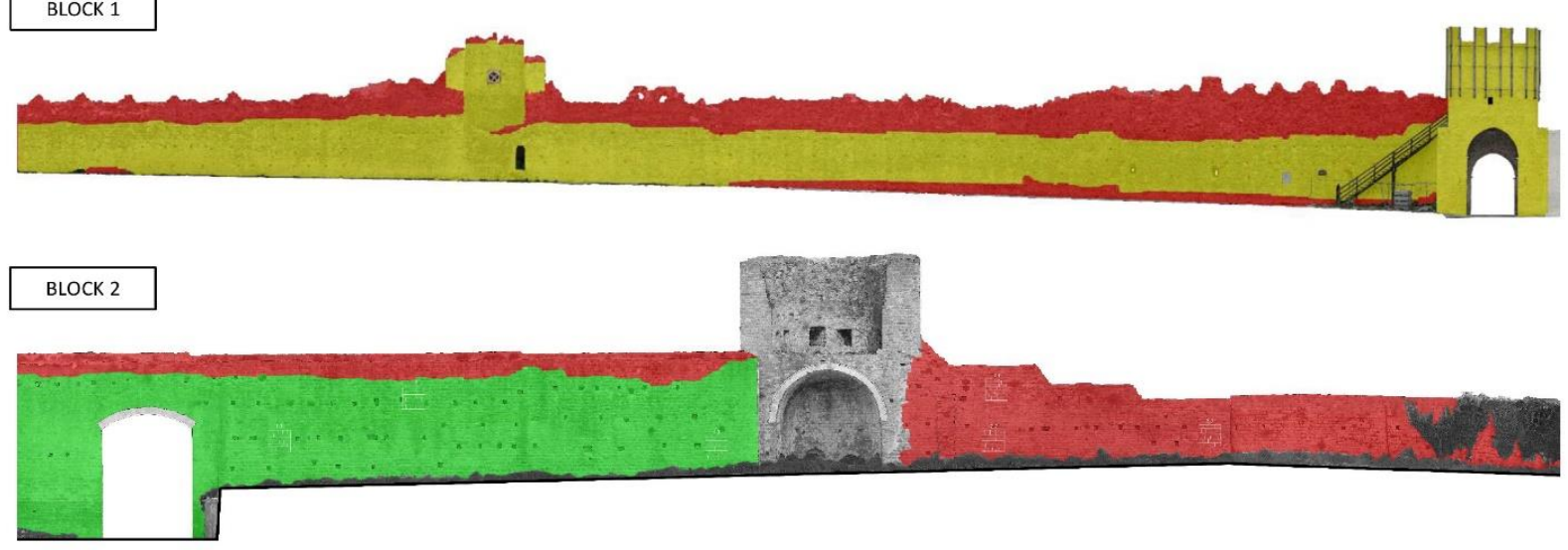

Figure 9: IQM identification of masonry categories 


\section{CONCLUSIONS}

The study allowed to identify the portions of the masonry that have a low quality and therefore a high vulnerability to seismic stresses, since under the effect of dynamic actions, would probably be disintegrated.

This assumption determines the need for a hierarchy of analyses and subsequent interventions, one preparatory to the other. In other words, before carrying out a numerical modeling of the structure, it will be necessary to guarantee a good quality of the masonry structures in order to be able, then, to analyze any local mechanisms or global behaviors. Moreover, the identification of uniform portions of masonry, will be able to limit the number of invasive analyses for the mechanical characterization of the structures. (double flat jacks)

Acknowledgements. Sincere thanks goes to the municipality of San Ginesio. A heartfelt, and special, thanks goes to all the students of the course of "Architectural Restoration" of UnivPM (academic year 2018/2019) for the passion and professionality showed.

\section{REFERENCES}

[1] Allevi F., Il balcone della Sibilla: San Ginesio fra cronaca e storia. A. Giuffrè, (1960).

[2] Salvi G., Memorie storiche di Sanginesio (Marche) in relazione con le terre circonvicine, Tipografia Savini, (1889).

[3] Cortella F., Da incastellamento a città: le mura urbane. In: P.F. Pistilli et al. (Eds.): La Chiesa Collegiata di San Ginesio. Una storia ritrovata, Centro Internazionale Studi Gentiliani - Quaderni (2012), pp. 13-48.

[4] https://www.dji.com/it (accessed on 25.05.2019)

[5] https://www.kaarta.com/products/stencil-2-for-rapid-long- range-mobile-mapping/\#Specs (accessed on 27.03.2019)

[6] Bronzino, G. P. C., Grasso, N., Matrone, F., Osello, A., and Piras, M., Laser-Visual-Inertial Odometry based solution for 3D Heritage Modeling: the Sanctuary of the Blessed Virgin of Trompone, Int. Arch. Photogramm. Remote Sens. Spatial Inf. Sci., XLII-2/W15, 215222, https://doi.org/10.5194/isprs-archives-XLII-2-W15-215-2019, 2019.

[7] https://www.agisoft.com (accessed on 02.05.2019)

[8] http://www.cloudcompare.org (accessed on 15.04.2019)

[9] Borri A., De Maria A., Scheda di valutazione dell'IQM (indice di qualità muraria), ReLUIS 3rd year report, Annex 3b.1-UR06-1 (2009)

[10] Borri A., De Maria A., Linee guida per la compilazione della scheda di valutazione dell'IQM, ReLUIS 3rd year report, Annex 3b.1-UR06-2, (2009)

[11] Borri A., De Maria A. Indice di qualità muraria (IQM) e correlazione con le caratteristiche meccaniche, (ReLUIS), (2015) Report WP1_1-1_2015,UNIPG,: http://www.reluis.it/images/stories/divulgazione/WP1 11_2015UNIPG_IQM_Report.pdf (accessed on 15.01.2020)

[12]Borri A., De Maria A. Il metodo IQM per la stima delle caratteristiche meccaniche delle murature: allineamento alla circolare n. 7/2019, Structural n. 222.; https://doi.org/10.12917/STRU222.06, (accessed on 15.01.2020) 